\title{
EVALUASI KUALITAS DAN PENGARUH WEBSITE GALERI MEDIKA TERHADAP KEPUASAN PELANGGAN MENGGUNAKAN METODE WEBQUAL 4.0
}

\section{Quality Evaluation and Effect of Medika Gallery Websites on Customer Satisfaction Using the Webqual 4.0 Method}

\author{
Rini Sulistyowati, s_rinies@yahoo.com ${ }^{1)}$, Dina Meisiana, mesianadina@gmail.com²) \\ ${ }^{1) 2}$ Sistem Informasi, STMIK-Indonesia, Jakarta
}

\begin{abstract}
This study aims to determine the effect of the quality of Galeri Medika's website based on WebQual 4.0 method which consists of three variables, namely usability quality, information quality and service interaction on user satisfaction. Data was collected through a questionnaire statement containing 26 statements to 60 respondents who were users of the Galeri Medika website. The data obtained is then processed using multiple linear regression analysis techniques. Based on data processing, it can be seen that the user's perception of the dimensions of user convenience, information quality, and service interactions are included in both categories. While based on the influence of these three variables, there are two variables that have a positive and significant effect on customer satisfaction, namely the dimensions of user convenience and the dimension of information quality. While the service interaction variable does not significantly influence customer satisfaction. Based on the results of the study, what should be focused is to improve the quality of service interactions
\end{abstract}

Keywords: webqual 4.0, respondent, variable

\begin{abstract}
ABSTRAK
Penelitian ini bertujuan untuk mengetahui pengaruh kualitas website Galeri Medika berdasarkan metoder WebQual 4.0 yang terdiri dari tiga variabel yaitu kualitas kegunaan, kualitas informasi dan layanan interaksi terhadap kepuasan pengguna. Data dikumpulkan melalui pernyataan kuesioner yang berisi 26 butir pernyataan kepada 60 responden yang merupakan pengguna website Galeri Medika. Data yang diperoleh kemudian diolah dengan menggunkan teknik analisis regresi linear berganda. Berdasarkan pengolahan data dapat diketahui bahwa persepsi pengguna dimensi kemudahan pengguna, kualitas informasi, dan layanan interaksi termasuk dalam kategori baik. Sedangkan berdasarkan pengaruh ketiga variabel tersebut terdapat dua variabel yang berpengaruh secara positif dan signifikan terhadap kepuasan pelanggan yaitu dimensi kemudahan pengguna dan dimensi kualitas informasi. Sedangkan variabel layanan interaksi tidak berpengaruh secara signifikan terhadap kepuasan pelanggan. Berdasarakan hasil penelitian maka yang harus difokuskan adalah untuk meningkatkan kualitas dalam layanan interaksi
\end{abstract}

Kata Kunci: webqual 4.0, responden, variabel

\section{PENDAHULUAN}

Perkembangan teknologi informasi khususnya dibidang internet semakin berkembang pesat. Internet (Interconnection Networking) ᄀadalah seluruh jaringan komunikasi yang menggunakan media elektronik yang saling terhubung menggunakan standar sistem global transmission control protocol / internet protocol suite (TCP / IP) sebagai protokol pertukaran paket (packing switching communication protocol) untuk melayani jutaan pengguna diseluruh dunia. Pertumbuhan internet ini turut 
memperngaruhi pertumbuhan perusahaan E-commerce di Indonesia.

Galeri Medika merupakan salah satu bisnis E-Commerce yang menjual alat-alat kesehatan melalui situs web. Website atau World Wide Web (WWW) adalah salah satu media penting dimana pengguna dapat menemukan semua jenis informasi yang berkaitan dengan bidang mereka sendiri. Website merupakan salah satu bentuk media massa yang dipublikasi melalui jaringan internet yang dapat diakses dimanapun dan kapanpun (Monalisa, 2016). Maka dari itu kelebihan website inilah yang kini banyak dikembangkan oleh perusahaan E-Commerce untuk menciptakan situs jual beli yang dapat diakses secara online di mana salah satunya adalah toko Galeri Medika yang menjual alat - alat kesehatan secara online.

Dalam rangka meningkatkan penjualan melalui online,untuk itulah kami ingin mengukur persepsi kemudahan persepsi kemudahan dan mengukur pengaruh kepuasan pelanggan dalam mengakses website galeri medika.Untuk mengukur kualitas layanan web tersebut maka dibutuhkan suatu metode yaitu webqual.WebQual adalah proses terstruktur dan disiplin yang menyediakan sarana untuk mengidentifikasi dan membawa suara pelanggan melalui setiap tahap pengembangan produk dan atau jasa dan pelaksanaanya.

\section{KAJIAN LITERATUR}

WebQual merupakan salah satu metode pengukuran kualitas website yang dikembangkan oleh Stuart Barnes dan Richard Vidgen (1998) berdasarkan persepsi pengguna akhir (end-user). Menurut Slabey (1990) dalam Barnes \& Vidgen (2003), WebQual adalah “...structured and disciplined process that provide a means to identify and carry the voice of the customer through each stage of product and or service development and implementation" yang artinya WebQual adalah proses terstruktur dan disiplin yang menyediakan sarana untuk mengidentifikasi dan membawa suara pelanggan melalui setiap tahap pengembangan produk dan atau jasa dan pelaksanaanya. WebQual sudah mulai dikembangkan sejak tahun 1998 dan telah mengalami beberapa interaksi dalam penyusunan dimensi dan butir pertanyaannya dengan metodologi Quality Function Deployment (QFD) yang merupakan sebuah sarana untuk mengidentifikasi dan membawa suara pelanggan melalui setiap tahap pengembangan produk dan juga jasa.

WebQual 1.0 merupakan versi pertama dari instrumen WebQual yang dikembangkan dalam domain website sekolah bisnis di UK (United Kingdom) dengan diselenggarakannya sebuah lokakarya dengan melibatkan enam siswa Master sebagai delegasinya. Hal yang dibahas pada diskusi tersebut adalah: "Apa saja kualitas website dari sekolah bisnis yang sangat baik?". Setelah melalui proses analisis tersisa 23 pertanyaan yang lalu kemudian dikelompokkan kedalam empat dimensi utama yaitu kemudahan penggunaan (ease of use), pengalaman experience), informasi (information), komunikasi (communication) dan integrasi (integration).

WebQual 2.0 diterapkan pada website B2C (Business to Consumer) yang menunjukkan dengan jelas bahwa perspektif interaksi kualitas dari suatu website tidak terwakili dengan baik pada WebQual 1.0. Pada WebQual 2.0 ini ditambahkan aspek kualitas interaksi dengan mengadaptasi hasil kerja dari SERVQUAL dan diaplikasikan pada domain toko buku online.

WebQual 3.0 ini indikator-indikator kualitas dikategorikan kedalam tiga kategori utama, yaitu: kualitas website, kualitas informasi dan kualitas interaksi. Ketika WebQual 1.0 begitu kuat pada kualitas informasinya namun kurang kuat pada interaksi layanannya. Begitu juga dengan WebQual 2.0 yang menekankan kualitas interaksi namun menghilangkan beberapa kualitas informasi dari WebQual 1.0. Versi baru dari WebQual 3.0 ini diujicobakan pada domain lelang online.

WebQual 4.0 merupakan hasil analisis pada WebQual 3.0 yang membawa pada 
identifikasi tiga dimensi dari kualitas website e-commerce, yaitu: kegunaan (usability), kualitas informasi (information quality) dan kualitas layanan interaksi (service interaction quality). Dalam WebQual 4.0 ini, kegunaan berkaitan dengan desain website misalnya penampilan, kemudahan penggunaan, navigasi dan juga tampilan yang disampaikan dalam website tersebut. Kegunaan fokus pada pandangan bagaimana pengguna melihat dan berinteraksi dengan website: apakah mudah bernavigasi? Apakah desain sesuai dengan jenis website? Lalu kualitas informasi merupakan kualitas dari isi website, yaitu kesesuaian informasi untuk penggunanya seperti format, tingkat akurasi dan juga relevansi. Terakhir ada kualitas layanan interaksi yang merupakan hal yang dialami oleh pengguna website, diwujudkan dalam bentuk kepercayaan dan empati misalnya mengenai transaksi dan keamanan informasi, pengiriman produk, personalisasi dan komunikasi dengan pemilik atau pengelola website.

\section{Tabel 1. Instrumen webqual 4.0}

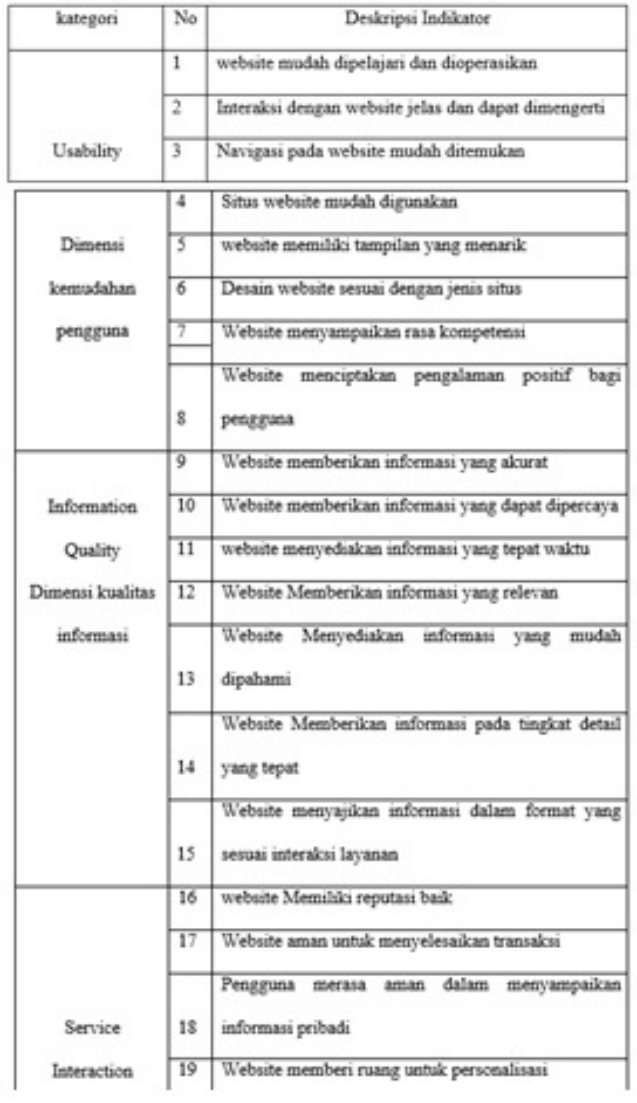

\section{METODE PENELITIAN}

Kerangka pemikiran merupakan model konseptual tentang bagaimana teori berhubungan dengan berbagai faktor yang telah diindentifikasi sebagai masalah yang penting. Kerangka pemikiran dibuat berdasarkan pertanyaan penelitian (research question), dan merepresentasikan suatu himpunan dari beberapa konsep serta hubungan diantara konsep-konsep tersebut. Komponen utama pada kerangka pemikiran adalah Independent Variables (variabel bebas), Dependent Variables (variabel terikat), Levels (indikator dari variabel bebas yang akan diobservasi), Measures (indikator dari variabel terikat yang akan diobservasi). Maksud dari kerangka pemikiran itu sendiri adalah bagaimana alur logika berjalannya variabel dalam penelitian. Dalam penelitian ini, penulis menyusun kerangka pemikiran sebagai berikut: 


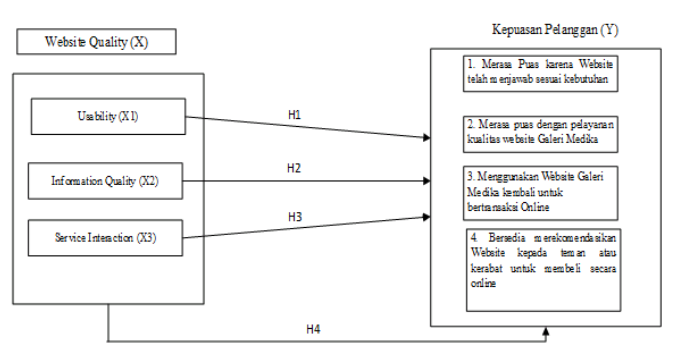

Gambar 1 Kerangka pemikiran

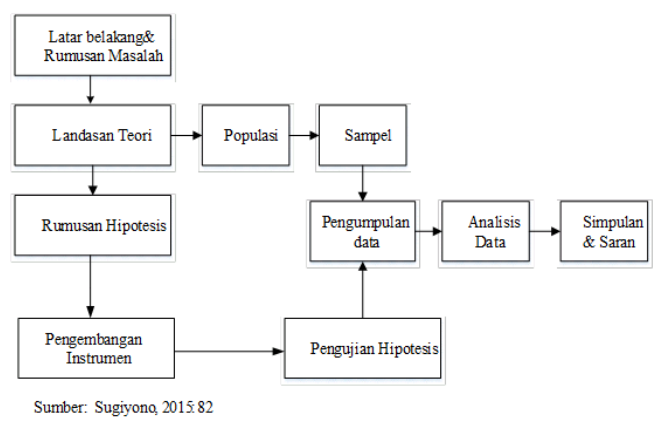

Gambar 2 Desain Penelitian

\section{HASIL DAN PEMBAHASAN}

Pada penelitian ini bertujuan menguji tingkat kematangan (maturity level) dalam penelitian ini menggunakan lembar pertanyaan kuesioner. Narasumber dalam penelitian ini adalah pelanggan Galeri Medika yang telah berbelanja maupun masuk di situs website galerimedika.com

\section{Tabel 2. Responden}

\begin{tabular}{|c|c|c|c|}
\hline No & Usia & Jumlah & Persentase (\%) \\
\hline 1 & $25-32$ & 112 & $74.7 \%$ \\
\hline 2 & $33-40$ & 30 & $20 \%$ \\
\hline 3 & $41-49$ & 4 & $2.7 \%$ \\
\hline 4 & $>50$ & 4 & $2.7 \%$ \\
\hline \multicolumn{2}{|c|}{ Total } & 150 & $100 \%$ \\
\hline
\end{tabular}

\section{Tabel 3 Pernyataan tentang Usability}

\begin{tabular}{|l|l|}
\hline No & \multicolumn{1}{|c|}{ Usability / Dimensi Kemudahan Pengguna } \\
\hline Q1 & Situs mudah untuk dipelajar dan dioperasikan \\
\hline Q2 & Website menciptakan pengalaman positif bagi pengguna \\
\hline Q3 & Website memiliki kompetensi \\
\hline Q4 & Website mudah untuk digunakan \\
\hline Q5 & Memiliki tampilan website yang menarik \\
\hline Q6 & Mudah untuk menemukan menu-menu didalam website \\
\hline Q7 & Interaksi dengan website ielas dan mudah dimengerti \\
\hline Q8 & Desain website yang cocok dengan jenis website \\
\hline
\end{tabular}

Tabel 4. Hasil pernyataan usability

\begin{tabular}{|c|c|c|c|c|c|c|}
\hline Keterangan & STS (\%) & TS (\%) & N (\%) & S (\%) & SS (\%) & $\begin{array}{c}\text { Total } \\
(\%)\end{array}$ \\
\hline Q1 & - & - & $\begin{array}{c}39 \\
(26 \%)\end{array}$ & $\begin{array}{c}98 \\
(65.3 \%) \\
\end{array}$ & $\begin{array}{c}13 \\
(4.7 \%)\end{array}$ & $\begin{array}{l}150 \\
(100 \%) \\
\end{array}$ \\
\hline Q2 & - & - & $\begin{array}{c}43 \\
(28.7 \%)\end{array}$ & $\begin{array}{c}100 \\
(66.7 \%)\end{array}$ & $\begin{array}{c}7 \\
(4.2 \%)\end{array}$ & $\begin{array}{c}150 \\
(100 \%) \\
\end{array}$ \\
\hline Q3 & - & - & $\begin{array}{c}51 \\
(34,0 \%)\end{array}$ & $\begin{array}{c}99 \\
(66,0 \%)\end{array}$ & - & $\begin{array}{c}150 \\
(100 \%)\end{array}$ \\
\hline Q4 & - & $\begin{array}{c}2 \\
\left(1_{2}^{3} \%\right)\end{array}$ & $\begin{array}{c}43 \\
(28,7 \%)\end{array}$ & $\begin{array}{c}89 \\
(59.3 \%)\end{array}$ & $\begin{array}{c}16 \\
(10.7 \%)\end{array}$ & $\begin{array}{c}150 \\
(100 \%)\end{array}$ \\
\hline Q5 & - & - & $\begin{array}{c}33 \\
(22.0 \%)\end{array}$ & $\begin{array}{c}110 \\
(73,3 \%)\end{array}$ & $\begin{array}{c}7 \\
(4.7 \%)\end{array}$ & $\begin{array}{c}150 \\
(100 \%)\end{array}$ \\
\hline Q6 & - & - & $\begin{array}{c}49 \\
(32.7 \%) \\
\end{array}$ & $\begin{array}{c}88 \\
(58,7 \%) \\
\end{array}$ & $\begin{array}{c}13 \\
(8.7 \%)\end{array}$ & $\begin{array}{c}150 \\
(100 \%) \\
\end{array}$ \\
\hline Q7 & - & $\begin{array}{c}14 \\
(9.3 \%)\end{array}$ & $\begin{array}{c}70 \\
(46.7 \%)\end{array}$ & $\begin{array}{c}64 \\
(42.7 \%)\end{array}$ & $\begin{array}{c}2 \\
(1,3 \%)\end{array}$ & $\begin{array}{c}150 \\
(100 \%) \\
\end{array}$ \\
\hline Q8 & - & - & $\begin{array}{c}41 \\
(27,3 \%)\end{array}$ & $\begin{array}{c}101 \\
(67.3 \%)\end{array}$ & $\begin{array}{c}8 \\
(5,3 \%)\end{array}$ & $\begin{array}{c}150 \\
(100 \%)\end{array}$ \\
\hline
\end{tabular}

Tabel 5 Pernyataan Information Quality

\begin{tabular}{|l|l|}
\hline No & \multicolumn{1}{|c|}{ Information Quality / Kualitas Informasi } \\
\hline Q9 & Website menvediakan informasi dengan detail yang tepat \\
\hline Q10 & Website menyediakan informasi yang mudah dimengerti \\
\hline Q11 & Website menyediakan informasi yang relevan \\
\hline Q12 & Website memberikan informasi yang tepat waktu \\
\hline Q13 & Website menyediakan informasi yang dapat dipercaya \\
\hline Q14 & Website menyediakan informasi yang akurat \\
\hline Q15 & Webste menyaiikan informasi dalam format yang tepat \\
\hline
\end{tabular}

Tabel 6 Hasil Pernyataan Information Quality

\begin{tabular}{|c|c|c|c|c|c|c|}
\hline Keterangan & $\begin{array}{l}\text { STS } \\
(\%)\end{array}$ & TS (\%) & N (\%) & S (\%) & SS (\%) & $\begin{array}{c}\text { Total } \\
(\%)\end{array}$ \\
\hline Q9 & - & - & $\begin{array}{c}8 \\
(5.3 \%) \\
\end{array}$ & $\begin{array}{l}106(7- \\
70,7 \%)\end{array}$ & - & $\begin{array}{c}150 \\
(100 \%)\end{array}$ \\
\hline Q10 & - & $\begin{array}{c}14 \\
(9,3 \%)\end{array}$ & $\begin{array}{c}63 \\
(42 \%) \\
\end{array}$ & $\begin{array}{c}73 \\
(48,7 \%) \\
\end{array}$ & - & $\begin{array}{c}150 \\
(100 \%)\end{array}$ \\
\hline Q11 & - & $\begin{array}{c}3 \\
(2, \%)\end{array}$ & $\begin{array}{c}43 \\
(33,3 \%) \\
(33 \%)\end{array}$ & $\begin{array}{c}100 \\
(60,2 \%)\end{array}$ & $\begin{array}{c}4 \\
(2,7 \%)\end{array}$ & $\begin{array}{c}150 \\
(100 \%)\end{array}$ \\
\hline Q12 & - & - & $\begin{array}{c}50 \\
(33,3 \%)\end{array}$ & $\begin{array}{c}92 \\
(61,3 \%) \\
\end{array}$ & $\begin{array}{c}8 \\
(5,3 \%)\end{array}$ & $\begin{array}{c}150 \\
(100 \%)\end{array}$ \\
\hline Q13 & - & $\begin{array}{c}2 \\
(13 \%)\end{array}$ & $\begin{array}{c}50 \\
(33,3 \%) \\
\end{array}$ & $\begin{array}{c}90 \\
(60.0 \%) \\
\end{array}$ & $\begin{array}{c}8 \\
(5,3 \%)\end{array}$ & $\begin{array}{c}150 \\
(100 \%)\end{array}$ \\
\hline Q14 & - & - & $\begin{array}{c}26 \\
(17 \% \%)\end{array}$ & $\begin{array}{c}116 \\
(77,3 \%) \\
\end{array}$ & $\begin{array}{c}8 \\
(5,3 \%)\end{array}$ & $\begin{array}{c}150 \\
(100 \%)\end{array}$ \\
\hline Q15 & - & - & $\begin{array}{c}46 \\
(30.7 \%)\end{array}$ & $\begin{array}{c}94 \\
(62,7 \%) \\
\end{array}$ & $\begin{array}{c}10 \\
(6,7 \%)\end{array}$ & $\begin{array}{c}150 \\
(100 \%)\end{array}$ \\
\hline
\end{tabular}

\section{Tabel 7 Pernyataan interaction}

\begin{tabular}{|c|l|}
\hline No & \multicolumn{1}{|c|}{ Service Interaction / Interaksi Layanan } \\
\hline Q16 & Memberikan produk atau layanan sesuai dengan janii \\
\hline Q17 & Menyampaikan rasa bermasyarakat atau bersosial \\
\hline Q18 & Dapat dengan mudah berkomunikasi dengan perusahaan \\
\hline Q19 & Menciptakan rasa personal atau teriaminnya privasi \\
\hline Q20 & Merasa aman dengan data pribadi pengguna \\
\hline Q21 & merasa aman dalam bertransaksi \\
\hline Q22 & Website memiliki reputasi vang baik \\
\hline
\end{tabular}

Tabel 8 Hasil Pernyataan interaction

\begin{tabular}{|c|c|c|c|c|c|c|}
\hline Keterangan & $\begin{array}{c}\text { STS } \\
\text { (\%) }\end{array}$ & TS (\%) & $\mathbf{N}(\%)$ & S (\%) & SS (\%) & $\begin{array}{c}\text { Total } \\
(\%)\end{array}$ \\
\hline Q16 & - & - & $\begin{array}{c}48 \\
(32.0 \%)\end{array}$ & $\begin{array}{c}98 \\
(65.2 \%)\end{array}$ & $\begin{array}{c}4 \\
(2.2 \%)\end{array}$ & $\begin{array}{c}150 \\
(100 \%)\end{array}$ \\
\hline Q17 & - & - & $\begin{array}{c}2 \\
(1.3 \%)\end{array}$ & $\begin{array}{c}118 \\
(78.7 \%)\end{array}$ & $\begin{array}{c}30 \\
(20.0 \%)\end{array}$ & $\begin{array}{c}150 \\
(100 \%)\end{array}$ \\
\hline
\end{tabular}

\begin{tabular}{|c|c|c|c|c|c|c|} 
Q18 & - & - & $\begin{array}{c}48 \\
(32,0 \%)\end{array}$ & $\begin{array}{c}98 \\
(65.3 \%)\end{array}$ & $\begin{array}{c}4 \\
(2.2 \%)\end{array}$ & $\begin{array}{c}150 \\
(100 \%)\end{array}$ \\
\hline Q19 & - & - & 44 & 104 & 2 & 150 \\
$(29.3 \%)$ & $(69.3 \%)$ & $(1.2 \%)$ & $(100 \%)$ \\
\hline Q20 & - & - & 42 & 104 & 4 & 150 \\
$(28.0 \%)$ & $(69.3 \%)$ & $(2.2 \%)$ & $(100 \%)$ \\
\hline Q21 & - & - & 55 & 91 & 4 & 150 \\
$(36.2 \%)$ & $(60.2 \%)$ & $(2.2 \%)$ & $(100 \%)$ \\
\hline Q22 & - & $\begin{array}{c}3 \\
(20 \%)\end{array}$ & $\begin{array}{c}60 \\
(40.2 \%)\end{array}$ & $\begin{array}{c}87 \\
(58.0 \%)\end{array}$ & - & $\begin{array}{c}150 \\
(100 \%)\end{array}$ \\
\hline
\end{tabular}

Tabel 9 Pernyataan kepuasan pelanggan 
\begin{tabular}{|c|c|c|c|}
\hline No & User Satisfaction / Kepuasan pelanggan \\
\hline Q23 & Sag
\end{tabular}

Q23 Saya merasa puas dengan kualitas pelayanan Galeri Medika

Q24 Saya merasa puas dengan produk yang ditawarkan Galeri Medika

Q25 Saya akan sering menggunakan Galeri Medika ketika berbelanja online

Q26 Saya bersedia merekomendasikan Galeri Medika kepada teman dan

Tabel 10. Hasil kepuasan pelanggan

\begin{tabular}{|c|c|c|c|c|c|c|}
\hline Keterangan & $\begin{array}{c}\text { STS } \\
(\%)\end{array}$ & $\begin{array}{c}\text { TS } \\
(\%)\end{array}$ & $\mathbf{N}(\%)$ & $\mathbf{S}(\%)$ & SS (\%) & Total (\%) \\
\hline Y1 & - & - & $\begin{array}{c}55 \\
(36,7 \%)\end{array}$ & $\begin{array}{c}95 \\
(63,3 \%)\end{array}$ & - & $\begin{array}{c}150 \\
(100 \%)\end{array}$ \\
\hline Y2 & - & - & $\begin{array}{c}25 \\
(16.7 \%)\end{array}$ & $\begin{array}{c}123 \\
(82 \%)\end{array}$ & $\begin{array}{c}2 \\
(1.3 \%)\end{array}$ & $\begin{array}{c}150 \\
(100 \%)\end{array}$ \\
\hline Y3 & - & - & $\begin{array}{c}91 \\
(60,7 \%)\end{array}$ & $\begin{array}{c}59 \\
(39.3 \%)\end{array}$ & - & $\begin{array}{c}150 \\
(100 \%)\end{array}$ \\
\hline Y4 & - & - & $\begin{array}{c}48 \\
(32,0 \%)\end{array}$ & $\begin{array}{c}100 \\
(66,7 \%)\end{array}$ & $\begin{array}{c}2 \\
(1,3 \%)\end{array}$ & $\begin{array}{c}150 \\
(100 \%)\end{array}$ \\
\hline
\end{tabular}

Tabel 11 Hasil rata-rata analisa deskriptif

\begin{tabular}{|c|c|c|c|c|c|c|c|}
\hline Keterangan & $\begin{array}{c}\text { STB } \\
(\%)\end{array}$ & $\begin{array}{c}\text { TB } \\
(\%)\end{array}$ & $\mathbf{C ~ ( \% )}$ & $\mathbf{B}(\%)$ & SB & $\begin{array}{c}\text { Kumulatif } \\
(\%)\end{array}$ & $\begin{array}{c}\text { Total } \\
(\%)\end{array}$ \\
\hline Usability & & & $\begin{array}{c}8 \\
(5.3 \%)\end{array}$ & $\begin{array}{c}106 \\
(70,7 \%)\end{array}$ & $\begin{array}{c}36 \\
(24 \%)\end{array}$ & $76 \%$ & $\begin{array}{c}150 \\
(100 \%)\end{array}$ \\
\hline Information & & & $\begin{array}{c}2 \\
(1.3 \%)\end{array}$ & $\begin{array}{c}118 \\
(78.2 \%)\end{array}$ & $\begin{array}{c}30 \\
(20.0 \%)\end{array}$ & $80 \%$ & $\begin{array}{c}150 \\
(100 \%)\end{array}$ \\
\hline $\begin{array}{c}\text { Service } \\
\text { Interaction }\end{array}$ & & $\begin{array}{c}91 \\
(60.7 \%)\end{array}$ & $\begin{array}{c}59 \\
(39.2 \%)\end{array}$ & - & $60 \%$ & $\begin{array}{c}150 \\
(100 \%)\end{array}$ \\
\hline $\begin{array}{c}\text { User } \\
\text { satisfaction }\end{array}$ & & $\begin{array}{c}6 \\
(4.2 \%)\end{array}$ & $\begin{array}{l}128 \\
(85.3 \%)\end{array}$ & $\begin{array}{c}16 \\
(10.7 \%)\end{array}$ & $89 \%$ & $\begin{array}{c}150 \\
(100 \%)\end{array}$ \\
\hline
\end{tabular}

Berdasarkan uji analisis deskriptif hasil analisis pada dimensi kemudahan pengguna diketahui nilai persentase kumulatif sebesar $76 \%$, dengan presentase tersebut, maka sub variabel usability masuk dalam kategori "baik". Namun pada sub variabel dengan butir pernyataan $\mathrm{Q} 4$ yaitu "website mudah untuk digunakan" terdapat $1,7 \%$ yang menjawab tidak setuju dan pada butir pernyataan Q7 yaitu"interaksi dengan website jelas dan mudah digunakan" memiliki nilai terendah $8,3 \%$. Hal ini menunjukkan bahwa website Galeri Medika kurang bisa memberikan interaksi yang website yang mudah digunakan.

\section{KESIMPULAN}

Berdasarkan hasil dari analisa dan pembahasan yang telah dilakukan, dapat diambil kesimpulan sebagai berikut:

1. Penilaian responden mengenai kualitas website Galeri Medika yang meliputi dimensi usability masuk dalam kategori "baik" dengan total skor kumulatif sebanyak 75\%. Pada dimensi information quality masuk dalam kategori "baik" dengan total skor kumulatif sebanyak $81,7 \%$. Pada dimensi service interaction mendapat total skor $60 \%$ masuk dalam kategori "cukup" sedangkan pada dimensi user satisfaction mendapat persentase tertinggi yaiu sebanyak $90 \%$ atau sangat baik.

2. Dalam uji T (parsial) dimensi webqual 4.0 memiliki pengaruh secara signifikan ialah variabel usabilty dan information quality. Sedangkan pada variabel service interaction tidak berpengaruh secara signifikan terhadap kepuasan pengguna.

3. Dalam uji F (simultan) dimensi 4.0 memiliki pengaruh secara simultan atau bersama - sama terhadap kepuasan pelanggan.

4. Pengaruh paling besar terhadap kepuasan pengguna adalah information quality sebanyak $81,7 \%$

\section{DAFTAR PUSTAKA}

[1] Abdullah, R. (2015:1). Web Programing is Easy. Jakarta: Elek Media Komputindo.

[2] Barner, S. \&. (2013). Measuring Website Quality Improvements: A Case Study Of the Forum on Strategic Management Knowledge Exchange. Industrial Management \& Data System.

[3] Bekti, H. (2015:35). Mahir Membuat Website Dengan Adobe Dreamweaver CS6, CSS, Dan Jquery. Jakarta: Andi Publisher.

[4] https://dhawyscientist.wordpress.com/2015/ 01/28/metode-pengendalian-persediaaneoqeconomically-order-quality/. (n.d.).

[5] Kotler, P. a. (2016). Marketing Managemen, 15th Edition. Pearson Education,Inc.

[6] Lupiyoadi, R. (2014:217). Manajemen Pemasaran Jasa. Jakarta: Salemba Empat.

[7] Monalisa. (2016). Analisis Kualitas Layanan Website Terhadap Kepuasan Mahasiswa. Jurnal Sains, Teknologi dan Industri, Vol. 13, No.2, Juni 2016, pp.181 $189,9$.

[8] Nasution, M. (2004:114). Manajemen Jasa Terpadu. Jakarta: PT. Ghalia Indonesia.

[9] Nilasari, S. (2014:2). Jago Membuat Website Gratis \& Cepat Secara Otodidak Edisi Terbaru. Dunia komputer. 
[10] Satori D dan Komariyah, A. (2014:200). Metodologi penelitian kualitatif. Bandung: Alfabeta.

[11] Sugiyono. (2015:334). Metode Penelitian Kombinasi (Mix Methods). Bandung: Alfabeta.
[12] Vidgen, S. B. (2001). WebQual: An Exploration of Website Quality. Bath: School Of Manajement, Universitiy of Bath. 